\title{
Large oil spill classification using SAR images based on spatial histogram
}

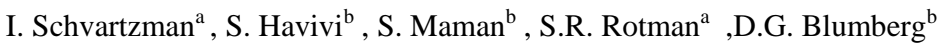 \\ ${ }^{a}$ Ben-Gurion University of the Negev, Electrical Engineering Department, 8410501 Beer Sheva, Israel - ilansc@post.bgu.ac.il \\ ${ }^{\mathrm{b}}$ Ben-Gurion University of the Negev, Department of Geography and Environmental Development, , 8410501 Beer Sheva, Israel
}

Commission VIII, WG VIII/9

KEY WORDS: Non-linear filter, Unsupervised Automatic Classification, Natural Hazards

\begin{abstract}
:
Among the different types of marine pollution, oil spill is a major threat to the sea ecosystems. Remote sensing is used in oil spill response. Synthetic Aperture Radar (SAR) is an active microwave sensor that operates under all weather conditions and provides information about the surface roughness and covers large areas at a high spatial resolution. SAR is widely used to identify and track pollutants in the sea, which may be due to a secondary effect of a large natural disaster or by a man-made one . The detection of oil spill in SAR imagery relies on the decrease of the backscattering from the sea surface, due to the increased viscosity, resulting in a dark formation that contrasts with the brightness of the surrounding area.

Most of the use of SAR images for oil spill detection is done by visual interpretation. Trained interpreters scan the image, and mark areas of low backscatter and where shape is a-symmetrical. It is very difficult to apply this method for a wide area. In contrast to visual interpretation, automatic detection algorithms were suggested and are mainly based on scanning dark formations, extracting features, and applying big data analysis.

We propose a new algorithm that applies a nonlinear spatial filter that detects dark formations and is not susceptible to noises, such as internal or speckle. The advantages of this algorithm are both in run time and the results retrieved. The algorithm was tested in genesimulations as well as on COSMO-SkyMed images, detecting the Deep Horizon oil spill in the Gulf of Mexico (occurred on 20/4/2010). The simulation results show that even in a noisy environment, oil spill is detected. Applying the algorithm to the Deep Horizon oil spill, the algorithm classified the oil spill better than focusing on dark formation algorithm. Furthermore, the results were validated by the National Oceanic and Atmospheric Administration (NOAA) data.
\end{abstract}

\section{INTRODUCTION}

Among the different types of marine environment pollution, large spills of oil and related petroleum products can lead to serious biological and economic impacts (Fingas \& Brown, 1997). There is an increasing need for monitoring large oil spills, estimating the location and extent of the spill (Fingas \& Brown, 1997; Fingas \& Brown, 2014). Remote sensing is an important part of oil spill response, as oil spills can be monitored on the open sea or ocean on a $24 \mathrm{~h}$ basis (Fingas $\&$ Brown, 2014).

Synesthetic Aperture Radar (SAR) is an active system transmitting electromagnetic waves, and measuring the backscatter, thus, different objects can be determined. The SAR uses resonant Bragg scattering mechanism (Wright, 1978), operating under all weather conditions, independent of external illumination, providing information about the surface roughness and covers large areas at high resolution. SAR is widely used to identify and track pollutants in the sea, which may be due to secondary effect of a large natural disaster or by a manmade one (e.g., a ship wreck).

The detection of oil spill by SAR imagery relies on the decreased backscattering from the sea surface, due to the increased viscosity, resulting in a dark formation that contrasts with the brightness of the surrounding area (Wismann, 1998).

A common way of observing an oil spill event is by visual inspection, by skilled observers seeking for changes between past images and current images, or looking for spatial patterns (Jones, 2001). Unfortunately, dark formation can be produced by plants, animals and man-made objects in the ocean sometimes creating false alarms.

Automatic classification algorithms are used for oil spill mapping. According to Topouzelis (2008), oil spill classification is composed of two main steps: (1) dark formation detection (2) validating the pixels that were marked as dark formation are indeed oil spills and are not oil look-alike. Usually, step 1 is done by some type of thresholding (before or after a low pass filter) and step 2 is performed by a statistical tool (such as pattern recognition or machine learning).

While most of the algorithms for oil spill detection in SAR require multiple polarization modes, and sometimes multi-look systems, this paper contains a novel method of large oil spill classification using a single polarization. The method makes use of bi-dimensional order statistics filtering, and therefore obtains the goal of the step 1 and step 2 at once. The proposed method is tested on simulations as well as on COSMO-SkyMed images, detecting the Deep Horizon oil spill in the Gulf of Mexico.

\section{RESEARCH AREA AND MATERIALS}

The Deepwater Horizon oil spill is the largest offshore discharge disaster in history (Garcia-Pineda, 2013). It was caused on April $20^{\text {th }} 2010$, by an explosion in the Gulf of Mexico, located at $28.74^{\circ} \mathrm{N} / 88.39^{\circ} \mathrm{W}$ (figure 1). The extent of the surface oil spill varied widely from day to day because of changes in wind patterns and ocean currents (Cleveland et al., 2010). The estimated amount of oil spilled was 4.1 million barrels of oil that contains around $2.1 \times 10^{10} \mathrm{~g}$ of polycyclic aromatic hydrocarbons, which is a toxic material arming wildlife and humans (Allan, 2012). Smith et al. (2011) estimated the economic impact of the event to be $36.9 \$$ billion. The described damage caused, stresses the need for oil spill automatic detection that can provide a more accurate and rapid assessment of such disaster.

COSMO-skymed, X-band SAR images of different locations and dates were used. Both data sets are from the Gulf of Mexico at the year 2010. The images are $5 \mathrm{~m} /$ pixel, georeferenced, and cover areas where the water was contaminated with Oil. One 
image was taken two weeks after the incident occurred, at VV polarization. The other around the time the spill ended at $\mathrm{HH}$ polarization.

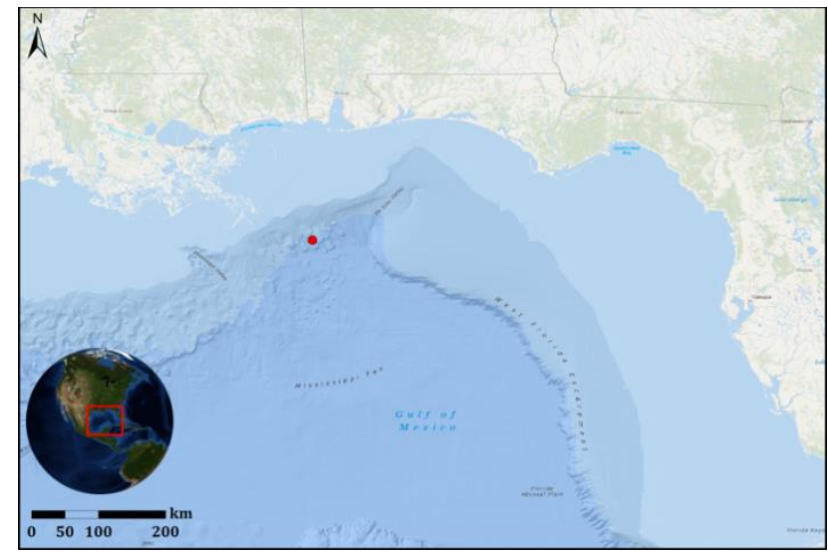

Figure 1. Gulf of Mexico research area. The red indicates the location of the source of the oil spill.

\section{METHOD}

The spatial histogram of areas with oil spill is significantly different than areas without oil spill. Due to speckle noise and oil spill look-alike, the histogram may not differ by its mean, min value or max value. In some cases we even found similar spatial median between areas with oil spill and without. We found the high values of the spatial histogram to be a more accurate estimator. Figure 2 describes a typical spatial histogram of areas with and without oil.

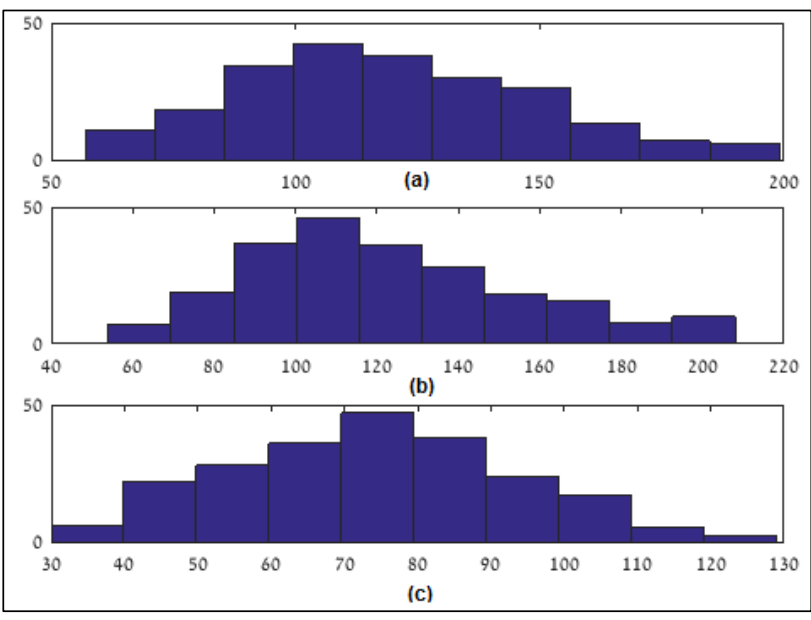

Figure 2. Spatial histograms of areas with and without oil spill

(a) without oil spill (b) without oil spill (c) with oil spill.

The algorithm includes a bi-dimensional spatial order filter (Haralick et al., 1992), which acts both as dark formation detection and feature extraction. Since we are dealing with large oil spills, this filter also omits look-alikes, than a threshold is applied according to the user's preferences.

\section{RESULTS}

\subsection{Simulations}

Simulations of oil spill and look-alikes were generated. The oil spill and the look a likes possess Gaussian noise, with mean 90, while the water was Gaussian noise with mean 120. Both had a standard deviation of 35. Multiplicative noise (speckle noise) was also added to the simulation as uniform noise in the range $0-3$. The simulation without the noise is given at figure 3 , and with the noise at figure 4 . The results of the algorithm appear at figure 5 .

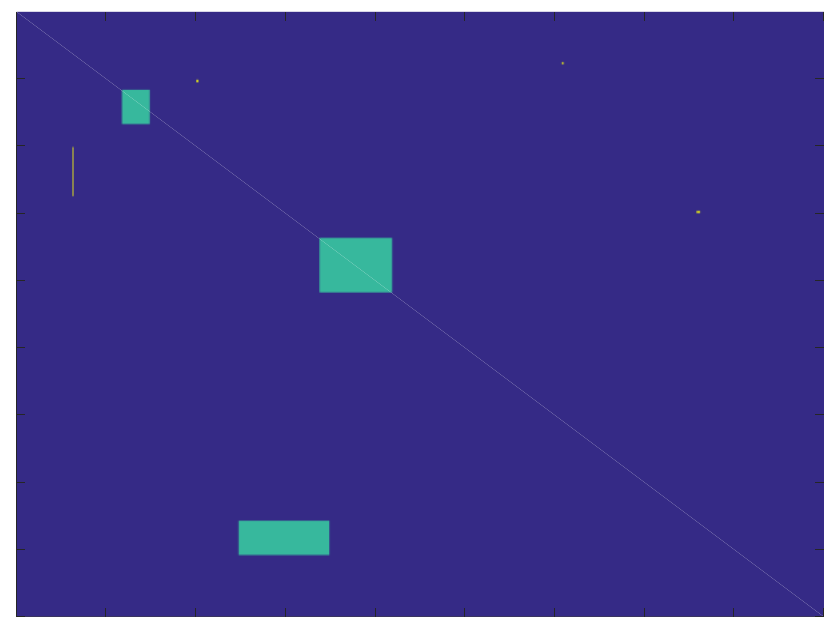

Figure 3. The simulation without noise, turquoise is water, blue is oil slick, and yellow is oil look-alike.

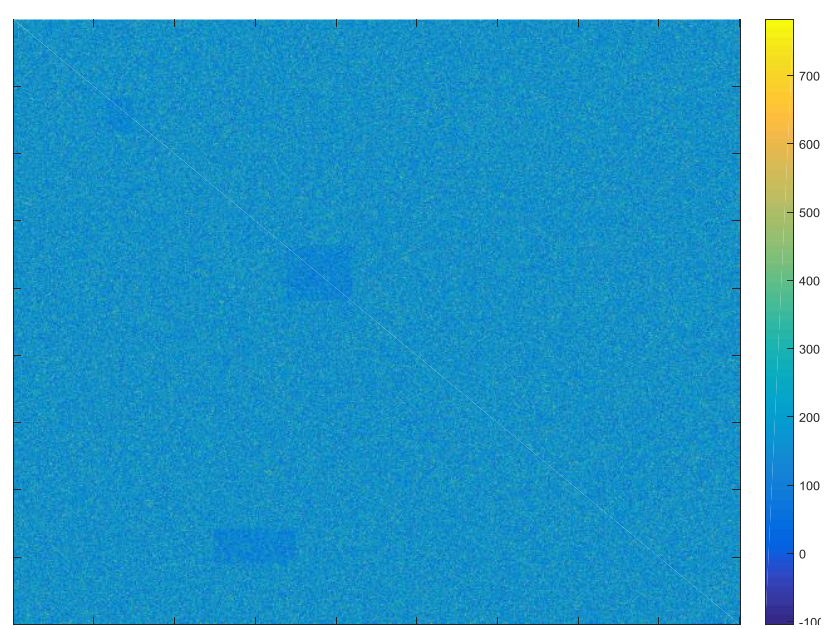

Figure 4. The simulation with the noise.

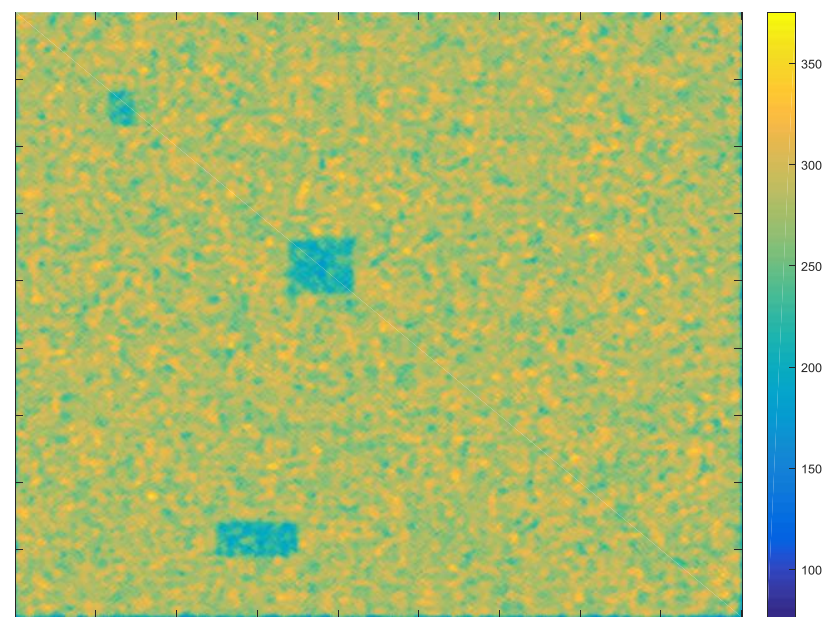

Figure 5. Product of applying the filter.

Figure 6 describes Receiver Operating Characteristic (ROC) curve created in a method described by Caefer et al., (2007). It 
contains the ROC curve created with different additive (denoted by $\sigma$ ) and multiplicative (denoted by speckle) noise.

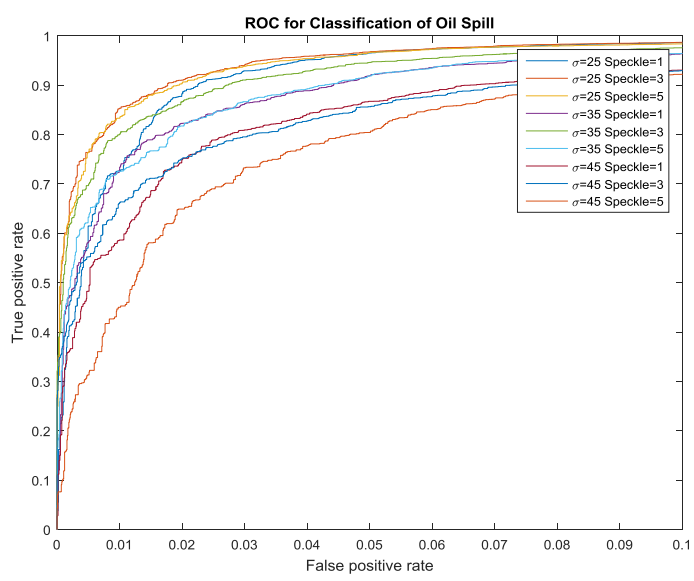

Figure 6. ROC curves for different noise levels.

\subsection{Deepwater Horizon Event}

The results are shown in figure 7 and figure 8 . Figure 7 describes ROC curves estimated for different validation data. The original SAR image was acquired on May $4^{\text {th }} 2010$. Since there is no reliable map of the oil spill for that day, we used estimation. Fortunately, there was a reliable map on May $8^{\text {th }}$. Other oil spill maps are also compared. Figure 8 describes ROC Curve estimated for different validation data. The original SAR image was acquired on July $16^{\text {th }} 2010$. In this case a reliable oil spill map was provided, from the same date as the image, therefore the algorithm had detected the oil spill with low false alarm rate.

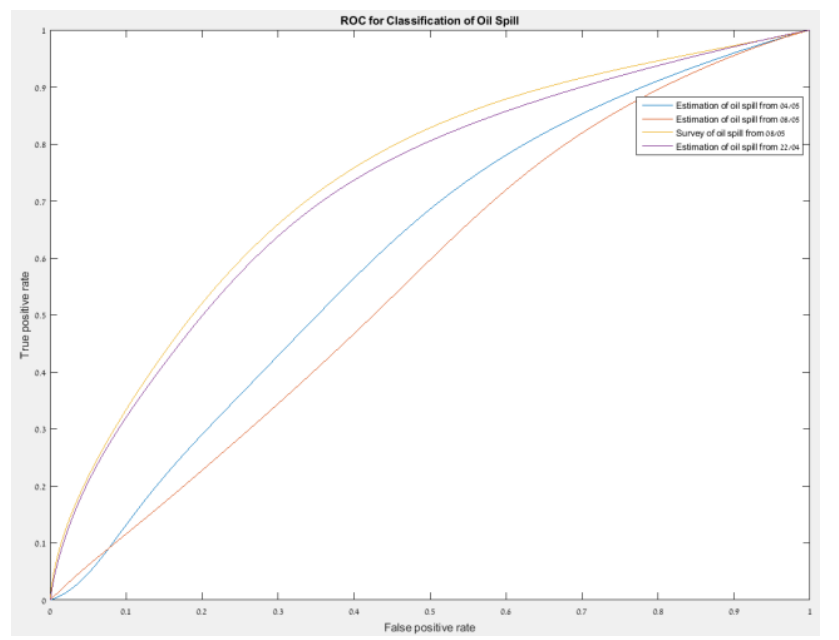

Figure 7. ROC curves for different validation data

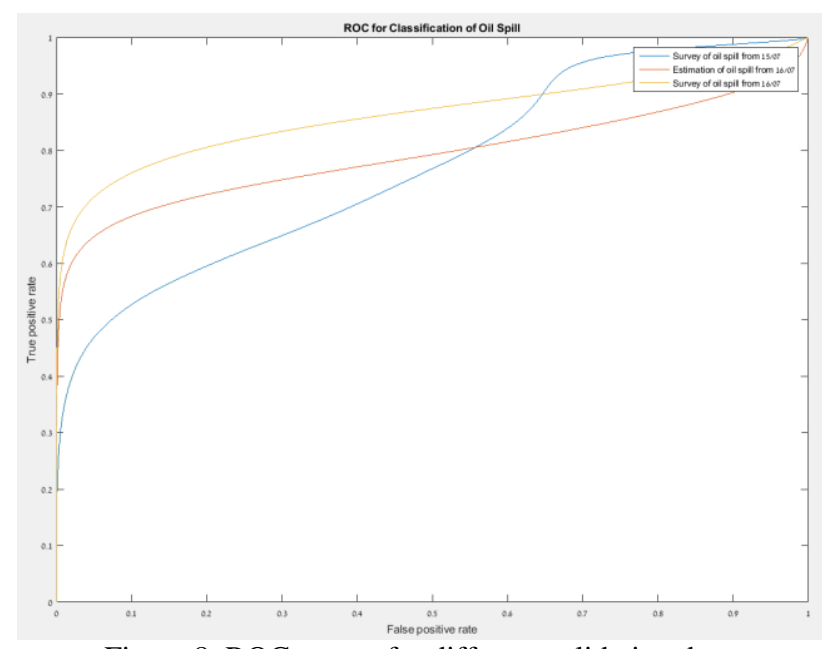

Figure 8. ROC curves for different validation data.

\section{CONCLUSIONS}

This work shows that single polarized SAR image can be used to detect large oil spill. Unlike other works that had to train a classifier (machine learning etc.), our algorithm is easier to implement, and there is no need for training sets. As opposed to Solberg (2007) claim that VV polarization is favourable for this purpose, our results with $\mathrm{HH}$ polarization, were found more accurate.

\section{ACKNOWLEDGEMENTS}

The authors wish to thank the Ministry of Science, Technology and Space of Israel, Italian Space Agency (ASI) and BGU for their partial support of this study.

\section{REFERENCES}

Allan, Sarah E., Brian W. Smith, and Kim A. Anderson. "Impact of the Deepwater Horizon oil spill on bioavailable polycyclic aromatic hydrocarbons in Gulf of Mexico coastal waters." Environmental science \& technology 46.4 (2012): 2033-2039.

Cleveland, C., Hogan, C.M., \& Saundry, P. (2010). Deepwater Horizon oil spill. The Encyclopedia of Earth

Caefer C. E., Stefanou M. S., Nielsen E. D., Rizzuto A. P, Raviv O., and Rotman S. R., "Analysis of false alarm distributions in the development and evaluation of hyperspectral point target detection algorithms," Opt. Eng. 467, 0764022007.

Fingas, M., \& Brown, C. (2014). Review of oil spill remote sensing. Marine pollution bulletin, 83, 9-23

Fingas, M.F., \& Brown, C.E. (1997). Review of oil spill remote sensing. Spill Science \& Technology Bulletin, 4, 199-208

Garcia-Pineda, O. et al. "Detection of floating oil anomalies from the Deepwater Horizon oil spill with synthetic aperture radar." Oceanography 26.2 (2013): 124-137. Smith, J., 1987a. Close range photogrammetry for analyzing distressed trees. Photogrammetria, 42(1), pp. 47-56.

Haralick, Robert M., and Linda G. Shapiro, Computer and Robot Vision, Volume I, Addison-Wesley, 1992. 
Jones, B. "A comparison of visual observations of surface oil with Synthetic Aperture Radar imagery of the Sea Empress oil spill." International Journal of Remote Sensing 22.9 (2001): 1619-1638.

Kubat, M., Holte, R. C., \& Matwin, S. (1998). Machine learning for the detection of oil spills in satellite radar images. Machine Learning, 30, $195-215$.

Marghany, Maged. "RADARSAT automatic algorithms for detecting coastal oil spill pollution." International Journal of Applied Earth Observation and Geoinformation 3.2 (2001): 191-196.

Marghany, Maged, and Mazlan Hashim. "Texture entropy algorithm for automatic detection of oil spill from RADARSAT-1 SAR data." Int. J. of the Phy. Sci 5.9 (2010): 1475-1480.

Smith, Lawrence C., Murphy Smith, and Paul Ashcroft. "Analysis of environmental and economic damages from British Petroleum's Deepwater Horizon oil spill." Albany Law Review 74.1 (2011): 563-585.

Smith, J., 2000. Remote sensing to predict volcano outbursts. In: The International Archives of the Photogrammetry, Remote Sensing and Spatial Information Sciences, Kyoto, Japan, Vol. XXVII, Part B1, pp. 456-469.

Solberg, Anne HS, Camilla Brekke, and Per Ove Husøy. "Oil spill detection in Radarsat and Envisat SAR images." Geoscience and Remote Sensing, IEEE Transactions on 45.3 (2007): 746-755.

Topouzelis, Konstantinos N. "Oil spill detection by SAR images: dark formation detection, feature extraction and classification algorithms." Sensors 8.10 (2008): 6642-6659.

Wismann, V., et al. "Radar signatures of marine mineral oil spills measured by an airborne multi-frequency radar." International Journal of Remote Sensing 19.18 (1998): 36073623 .

Wright, J.W.,1978, Detection of ocean waves by microwave radar: the modulation of short gravity-capillary waves. Boundary Layer Meteorology, 13, 87-105. 